\section{Aid and Poverty Alleviation An International Comparison} Yasuyuki Sawada

\section{Introduction*}

The international aid provided to developing countries since the Second World War has been considerable. There is, however, a substantial controversy over the motivation behind foreign aid and the contribution to development of aid provision (Meier 1995: 224). Proponents argue that aid provides mutual benefits for donors and recipients through its contribution to a more stable world economy. Some economists disagree with this conventional view by arguing that aid is generally of limited value as an instrument of development. The estimation of welfare functions suggests that donors as a whole have significant inequality aversion in the international distribution of aid and that various incentives exist for bilateral aid provision (Behrman and Sah 1984). The first and most obvious is national interest (Cassen et al. 1986: 269). Donors support countries with whom they have cultural, economic, political, or strategic ties. Donors may consider direct economic or strategic benefits. Domestic politics may also determine the directions and characteristics of bilateral aid provisions. For some donors, however, humanitarian motives seem to be prevalent. In sum, aid donor countries may be concerned with such issues as mutual benefits, potential economic and political benefits for themselves, poverty alleviation, equity, and international security. On the other hand, motivation for multilateral aid can be said to be more transparent. Multilateral agencies are largely apolitical and more exclusively concerned with development (Cassen et al. 1986: 281). For instance, the policy statements of multilateral irsstitutions such as the World Bank and the United Nations have stressed the importance of income equalization and poverty alleviation for recipients.

In the 1970s, issues of income distribution and poverty had emerged as new international problems. An influential study concluded that a solution lay not in suspension of a growth objective but in

\footnotetext{
* This is a revised version of the paper prepared for the workshop, 'Poverty, Policy and Aid', at IDS on 13-14 September 1995. I would like to thank workshop participants, especially Bob Baulch, Andy Mason, Simon Maxwell. John Toye and Howard White for useful suggestions. Comments from Fred Zimmerman, Tim Josling, Michikazu Kojima, Scott Pearson, and Pan Yotopoulos are also helpful. Any remaining errors, however, are the author's.
} 
redistribution of the benefits of growth (Chenery et al. 1974). New approaches which emphasize alternative development objectives such as the basic human needs (BHN) have emerged. These new streams in the research and practices in development triggered several new approaches of international aid which focus on the issues of poverty. Since the 1970s, almost all aid donors have realized the importance of poverty alleviation. Most aid agencies have a commitment to eliminate poverty and many have written it into their charters. A new set of strategies such as aid to establish equitable growth, aid to poor countries, and direct transfer to the poverty group has been employed by donors and international institutions. Although poverty remains widespread, aid has directly and indirectly helped countries to alleviate poverty (Cassen ct al. 1986).

The World Bank's 1990 World Development Report articulated the importance of policy reform to reduce poverty and provided the basis for a better aid strategy (World Bank 1990). In order to reduce poverty, the Report recommends that 'external assistance should be more tightly linked to an assessment of the efforts that would-be recipients are making to reduce poverty' (ibid.: iv). In countries where policies are inconsistent with efforts to reduce poverty, foreign aid will achieve far less. Hence, to alleviate poverty effectively, the recipients' policy should be appropriate. In this article, we call this requirement the first necessary condition for poverty alleviation. However, there is a second necessary condition to be satisfied by donors: aid should be expanded towards the countries where the poverty is most widespread and not to the relatively developed countries.' When aid has not been targeted to the poor countries, the results have some limes been unsatisfactory even in a country which satisfies the first necesary condition (World Bank 1990: iv)

This article extends Besley and Kanbur (1988)s approach to targeting food subsidies to the interna. tional aid provisions and provides some evaluation results for the second necessary condition, that is, whether donors aid allocations are designed to reduce poverty. We will quantitatively compare the global poverty alleviation effect of the aid provided by Japan, the UK, the US, the Development Assistance Committee (DAC) of the OECD, and the multilateral organizations. A consistent evaluation framework together with Chen et al. (1993)'s head count data comparable across countries is employed. This analysis would he classified under the traditional income/consumption approach to poverty measurement in the Baulch (1996) framework. Disaggregated studies on aid, such as the project and sectoral approaches discussed in White (1996) and the institutional analysis of Maxwell (1996) complement the results in this article

\section{The Second Necessary Condition of Aid to Alleviate Poverty}

\subsection{A framework to analyse poverty}

To quantitatively examine the second necessary condition for several donors, we need to define an indicator of poverty. Theoretically, there are two types of social welfare measures - an exclusive measure, which attaches zero weight to levels of living above some poverty line, and an inclusive measure giving positive weight to the entire distribution (Ravallion 1994). These typically are called the poverty measure and income distribution measure, respectively. Although the choice of measure can depend on various factors such as theoretical consistency and tractability, from a practical point of view, there is enough co-inovement between exclusive and inclusive measures (Ravallion 1994). As a typica! exclusive measure, we can define an index of the global poverty gap, $G$, following Foster et al. $(1984)$ :

\footnotetext{
1 To test the sufficient condition, we need to compare the poverty alleviation outcome of each aid provisions. This task, however, involves difficulties of measurement and comparability.
}

This measure satisfies several desirable properties such as the Sen (1976)'s Monotonicity Axiom, additive decomposability with population-share weights, and inclusion of a relative deprivation concept of poverty The Transfer and Transfer Sensitivity Axioms, however, are not satisfied. 


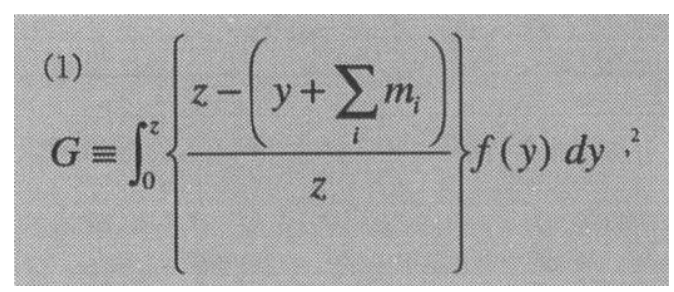

where $z$ and $y$ represent poverty line consumption level and consumption level without aid, respectively. In equation (1), $m(i)$ is the total amount of international aid per capita provided by a donor country $i$. Hence, this measure captures a potential effect of aid to increase the recipients' consumption. The proportion of the population who consume the amount $y$ is represented by $f(y)$. This poverty gap measure is a weighted sum of poverty population share in the world. A normalized squared distance of each household's consumption from poverty line is employed as a weight, which means that the weight is higher for the poorer households. This global poverty gap measure in equation (1) can be decomposed into an additive form of each recipients' poverty gap (Foster et al. 1984). Then, following Besley and Kanbur (1988), the global poverty gap reduction effect of the country i*'s additional aid provision can be derived from equation (1):
The intuition behind the equation (2) should be clear. Given other donor's aid provisions, a donor's additional aid transfer to country $j$ potentially increases everybody's consumption in the country $j$ by the same small amount. If a high percentage of the recipient's population belongs to consumption classes below the poverty line, then a relatively high proportion of people can benefit from this aid provision. Hence, the poverty gap decline will be relatively significant. On the other hand, if there is nobody below the poverty line, i.e., head count ratio is zero, the poverty gap measure cannot be changed by this additional aid transfer.

Another striking point of this framework is that this criteria is independent of absolute population scale. The intuition behind this is also simple. Let us think about a case where the same amount of aid is provided to all recipients. A small country can enjoy the large poverty alleviation effect since per capita aid received is large for the small country. This positive effect becomes larger as the population of the recipient is smaller. On the other hand, the impact of aid provision to this small country on the global poverty gap is insignificant as the recipient has a small share in the world population. The former and the latter effects cancel

$$
\left.d G\right|_{M_{v}=0 \forall i \neq i^{*}}=-\left(\frac{1}{z}\right) \times \sum_{j}\left\{(\text { Head Count Ratio of Recipient } j) \times d M_{i * j}\right\}
$$

where $M\left(i^{*}, j\right)$ is the absolute amount of aid disbursed from donor $i *$ to recipient $j$. This equation (2) indicates that if the objective of the donor $i$ *'s aid provision is to minimize the global poverty gap, $G$, then the recipient with the higher poverty population share should be targeted at the margin. ${ }^{3}$ The policy conclusion derived becomes that additional international aid of country $i^{*}$ should be allocated towards countries with high head count ratios. Hence, this donor strategy will be a testable criteria of the second necessary condition. out each other and thus the poverty alleviation effect becomes independent of recipients' population scale. We should note, however, that the test results based on equation (2) do not mean that reallocating a given amount of aid between poor countries will reduce the degree of poverty, since the poverty gap measure represented by equation (1) is not sensitive to a redistribution of income among the poor. ${ }^{4}$ Instead, the results should be interpreted as that there are alternative rules for donors' aid expansions which might have a greater

\footnotetext{
${ }^{3}$ To derive this conclusion, the Monotonicity Axiom is required. As shown in Foster et al. (1984)'s proposition 1 , the poverty gap measure satisfies the Monotonicity Axiom.
}

4 This is because the poverty gap measure does not satisfy the Transfer Sensitivity Axiom (Foster et al. 1984). 
effect on poverty alleviation. ${ }^{5}$ This means that the second necessary condition can be tested at the margin of aid allocations in our framework.

\subsection{Data for international comparison}

Conventionally, average income per capita of recipients is employed as a yardstick or a first approximation to describe the effect of aid (White and McGillivray 1995). However the results derived from the per capita income measure may be misleading, since they ignore the difference of the income or consumption distribution between recipients. This paper employs a more desirable measure, the head count ratio, which the theory requires to test the second necessary condition, and which takes account of the distribution of income between the poor and non-poor.

Country level estimates of various poverty measures can be found in many empirical studies. These studies, however, have usually used poverty lines appropriate to each country and the cross-country comparability of data has been an issue. Comparisons of the head count ratio should ideally use a poverty line, $z$, in a consistent fashion across countries. US dollar conversion of amount of aid using official exchange rates may be misleading since poor people usually consume significant amount of nontraded goods. Moreover, deviations of nominal exchange rates from their equilibrium values are widely observed in developing countries. So international currency conversion using purchasing power parity (PPP) exchange rates is much better than conversion by official foreign exchange rates when living standards of countries are compared

\footnotetext{
"This interpretation is valid since the poverty gap measure satisfies the Monotonicity Axiom (Foster et al. 1984).

${ }^{6}$ For these estimations, the Lorenz Curves are derived from results of household expenditure surveys (Central Bureau of Statistics 1985, 1992, Korayem 1994), consumption PPP data are extracted from Summers and Heston (1991), and macroeconomic data are taken from World Tables of the World Bank and International Financial Statistics of the IMF. Then the head count ratios are estimated by assuming log-normal distribution for the consumption distribution function.

7 Conceptually for the purpose of this paper, the best thing to do would be to have grants plus the grant element of loans, but this will be difficult from a data
}

(Chen et al. 1993). With the PPP conversion, poverty lines in all countries are set so as to maintain a constant purchasing power of the poverty line across countries. Chen et al. (1993) calculated an internationally comparable poverty line by employing the consumption PPP estimated by the International Comparisons Project (Summers and Heston 1991). We will employ Chen et al. (1993)'s estimates of head count ratios with $\$$ US21 per month at 1985 PPP as the poverty line consumption, i.e., $z=\$$ US2l per month, which corresponds to the estimated poverty lines for the poorest countries. We also estimated the head count ratios for Israel and Egypt through the procedure proposed by Chen et al. (1993). ${ }^{\circ}$

Following White and McGillivray (1995)'s argument on the choice of aid variable, we present results based on both gross ODA disbursements and aid commitment, although we use aid measured in absolute rather than per capita terms for the reason mentioned above. Commitments are thought to be the donor's decision variable since they are amounts made available by donors. On the other hand, the amount of actual aid provision, gross ODA disbursements, are affected by both donor and recipient (White and McGillivray 1995: 166-167). ${ }^{7}$ Data is extracted from OECD (1989, 1993). Comparisons between Japan, the UK, the US, total grants by the Development Assistance Committee (DAC), and multilateral institutions are considered. After checking data availability, we were left with 40 and 39 recipients of international aid in 1985 and 1990 , respectively. The coverage of recipients' population is around 80 per cent and that of aid provisions is 50 to 80 per cent. ${ }^{8}$

point of view. Alternatively, if the data of aid for social infrastructure, agricultural production, and food are available on a recipient country basis, it would be possible to obtain better transfer measure. Regression analysis using these data and head count ratios could extract the pure effect of aid on poverty alleviation. Information derived from the disaggregated approaches will also be useful (White 1995; Maxwell 1995).

\footnotetext{
${ }^{8}$ The population coverages in 1985 and 1990 are 79 per cent and 78 per cent of total population of all aid recipients, respectively. The coverages in 1990 commitments are 75 per cent, 59 per cent, 83 per cent, 64 per cent and 57 per cent of total ODA commitments of Japan, the UK, the US, the DAC, and multilateral institutions, respectively.
} 


\subsection{Marginal efficiency of Allocation}

One testable version of the second necessary condition for poverty alleviation in equation (2) is the condition that, if a county's object of international aid expansion is poverty alleviation, then the rank of head count ratio and of further aid provisions should be positively correlated. To see this marginal efficiency of poverty alleviation quantitatively, Spearman's rank correlation coefficient between head count ratio rank and aid provision rank is calculated. This coefficient can be interpreted as the marginal efficiency of a recipient's aid provision ranking: If it is one, further expansion of aid provision following the current ranking is completely efficient in terms of poverty alleviation. If it is negative, major revision of allocation ranking would be required for aid expansions to have a significant effect on poverty alleviation.

Rank correlation results for Japan, the UK, the US, the total DAC members, and multilateral institutions are compared in Table 1 and Table 2. Table 1 reports the results using the ODA commitment data. The results from gross ODA disbursements are presented in Table 2. In both years, the multilateral relatively inefficient in terms of poverty alleviation. Moreover, it is implied that Japanese aid commitments are adversely affected by actual operations, since the coefficients of disbursements are smaller than those of commitments. There are small but slightly positive rank correlations between head count ratio and aid allocation share for the US. We should note, however, that exclusion of Israel and Egypt improves the coefficients for the US. This implies that the Economic Support Fund (ESF) does not follow the global poverty minimization standard. Instead, political and strategic factors obviously influence US aid provisions to these two countries. Finally, comparisons between these two periods imply the marginal efficiency of provision ranking worsened for Japan, the UK, total DAC but improved slightly for the US and for multilateral institutions.

\subsection{Potential effectiveness at the margin}

To evaluate the quantitative impact of additional aid on poverty reduction, we can define the average poverty alleviation effect of each donor's aid, APAE. This measure is derived from a modification of equation (2) as:

$$
\operatorname{APAE}(i)=-\left(\frac{1}{z}\right) \times \sum_{j}\left\{(\text { Head Count Ratio of Recipient } j) \times\left(\begin{array}{c}
M_{i j} \\
M_{i}
\end{array}\right)\right\}
$$

institutions had the most efficient commitment ranking and actual aid disbursement ranking. The UK also has a high allocation efficiency among the recipients considered. For these two donors, it is also implied that the less efficient commitment rankings have been positively affected by the actual implementation process and no major revisions of allocation rankings would be required for the further aid provisions. In contrast, Japan's allocation ranking does not really reflect the incidence of poverty since the rank coefficients are negative or small. In other words, Japanese aid expansion is where $M(i)$ is total aid provision of a donor $i$. This is a negative linear function of the average of head count ratio with the aid allocation share used as weights. Given the current provision rankings of each donor and the assumption that the first necessary condition for the recipient is fully met, this measure captures the poverty alleviation effect of an additional US dollar aid allocated by donor $i .^{9}$ In this sense, the APAE is a measure of potential poverty alleviation effect and thus can be used as a testable measure of the second necessary condition. As a donor's APAE decreases, this donor's aid

\footnotetext{
- Since this measure considers a potential maximum effect of aid, the APAE cannot be positive by construction. However, actual effects may be smaller if there are aid programmes that are not targeted on the poor. For this point, we can obtain useful insights from the project, the sectoral, and the institutional approaches (White 1995; Maxwell 1995).
} 
provision becomes potentially more effective in poverty reduction.

There are both similarities and differences between the rank correlation results and the results of the APAE estimation reported in Table 3 and Table 4. In both years, the multilateral institutions and the UK have determined and implemented the relative quantity of aid in the most effective manner among the donors considered. The UK had the lowest APAE measure for aid commitment in 1990 and also for actual aid disbursement in 1985 and 1990. For 1990 aid commitment, the APAE measure is lowest for multilateral institutions. It is implied that these two donors kept not only the efficient provision rankings but also the effective relative allocation magnitude at the margin. Hence, in terms of poverty alleviation, their aid allocation and expansion principle might have be reasonably justified. On the other hand, Japan and the US had the worst effectiveness in 1990 and 1985, respectively, for both allocation decisions and actual disbursements. Negative rank correlation results and the poor performance indicated by APAE of Japan suggest that Japan's aid provision is relatively ineffective in terms of marginal poverty alleviation. Japan's aid expansion should have been revised not only to adjust the disproportionate aid allocations but also to induce major change in the allocation ranking. The slightly positive rank correlations and low APAE measures for US aid indicate the existence of excessive aid provision to Israel and Egypt; in terms of global poverty alleviation, major revisions to the volume of aid allocated to these countries are required. The changes in APAE measures between the two periods suggest a decline in poverty alleviation effectiveness for Japan, the UK, and multilateral institutions and an increase for the US.

\section{What are Japan's Ald Objectives?}

Evaluation results of marginal allocation efficiency and potential effectiveness of aid expansion in Section 1 imply that the second necessary condition for poverty alleviation may not be satisfied for Japan. Before deriving definitive conclusions, this section discusses Japan's aid system and objectives in detail.

\subsection{Japan as a major donor}

In the 1970s and 1980s, foreign aid becomes one of Japan's leading foreign policy tools. Nowadays, Japan is one of the major actors in the international aid arena and is currently making a tremendous contribution to international development assistance. Since 1990, the Japanese government has been the second largest donor of bilateral official development assistance. The two notable characteristics of Japan's ODA are the high percentage of loans and of aid for economic infrastructure. Unlike other leading donors, Japan has chosen not to give aid to military allies or former colonies.

The structure of Japan's foreign bilateral aid can be divided into two parts: Grants disbursed by the Japan International Cooperation Agency (JICA) ${ }^{10}$ and loans provided by the Overseas Economic Cooperation Fund (OECF). For grants, actual policy decisions are executed mainly by the Economic Cooperation Bureau of the Ministry of Foreign Affairs (MOFA). Four ministries, MOFA, the Ministry of Finance (MOF), the Ministry of International Trade and Industry (MITI), and the Economic Planning Agency (EPA), are responsible for directing loan disbursements.

\subsection{The decision making process, philosophy, and reality of Japan's aid}

The Japanese aid programme involves a complex decision making process. The responsibilities for aid administration are divided among the above mentioned four main ministries, MOFA, MOF, MITI, EPA, plus 12 other ministries and agencies concerned with particular types of projects. Conflict between these responsible ministries and agencies has confused the purpose of Japan's aid and obstructed effective direction of the programme (Yasutomo 1986, Orr 1990, and Rix 1990).

\footnotetext{
10 JICA also supervises the Japan Overseas Cooperation Volunteers (JOCV) composed of about 900 volunteers in 54 countries in 1991 .
} 
Aid by the Japanese government is given mainly as an international obligation, both to assist world peace and prosperity and as a foreign policy mechanism to preserve Japan's peace and prosperity. In a publication, Philosophies of Economic Cooperation: Why Official Development Assistance? issued in 1980, the Ministry of Foreign Affairs stated that, officially, Japan's economic cooperation is guided by two rationales: 'humanitarian and moral considerations' and 'the recognition of interdependence among nations' (Ministry of Foreign Affairs 1994). On June 30, 1992, the Japanese Cabinet adopted Japan' Official Development Assistance Charter (ODA Charter), in which philosophies and objectives are extended. With regard to the basic philosophies of Japan's ODA, the ODA Charter lists (i) humanitarian considerations, (ii) recognition of interdependence among nations of the international community, (iii) environmental consideration, and (iv) support for self-help efforts of recipient countries (Ministry of Foreign Affairs 1994).

However, the effectiveness of Japanese foreign aid has been widely disputed in the press. Some argue that Japan's economic aid is only beneficial to the Japanese economy and that there has never been a highly moralistic rationale for aid in Japan, while others maintain that Japanese aid has been directed towards practical, even pragmatic, ends (Rix 1990). Notably, in comparison to aid from other leading donors, a higher proportion of Japan's total ODA is in the form of loans, while a lower proportion of ODA is through grants. This implies that Japan's massive quantity outlays still fall mainly in the hard and non-humanitarian end of the ODA spectrum, and that most other DAC donors have an aid programme softer on the recipient (Rix 1990). The evaluation results in Section 2 may indicate that these criticisms of Japan's aid are basically accurate, although, officially, Japan's aid has a much stronger humanitarian emphasis, as can be seen in the BHN approach initiated in the late 1970s.

The results, however, should not be interpreted to indicate that Japan's ODA is completely ineffective in reducing poverty. Japan's aid potentially has helped countries to reduce poverty. It may be obvious that Japanese aid to the East and Southeast Asian countries has contributed not only to macroeconomic economic growth but also to poverty alleviation. Moreover, the rigidity of Japan's aid allocation with the past successful aid provisions might be a cause of the negative evaluation results in this article. An appropriate interpretation of the results may be that, from a global perspective, there was an alternative way for Japan's ODA to be expanded to contribute more to poverty alleviation in 1985 and 1990.

\section{Concluding Remarks}

This paper evaluates the poverty alleviation effect of international aid provided by the governments of Japan, the UK, the US, the DAC, and multilateral organizations. A consistent poverty evaluation framework together with head count ratio data is employed to test the second necessary condition of aid to alleviate poverty. Rank correlation results and weighted average measures indicate that marginal aid allocation by the government of Japan has been relatively inefficient and ineffective in terms of poverty alleviation. On the other hand, in both years, the UK and multilateral institutions have been most effective in reducing global poverty at the margin among the donors considered. Hence, in terms of poverty alleviation, their aid allocation principle might be justified for further aid expansions. Slightly positive rank correlations and relatively poor APAE measures for US aid indicate that major revisions of the amounts disbursed under the ESF are required to improve the efficiency and marginal effectiveness of US aid in terms of poverty alleviation. The change in these measures between the two periods suggests a decline in poverty alleviation effectiveness for Japan and the UK, and an increase for the US.

So far, we have focused on the second necessary condition for foreign aid to reduce poverty. This condition should be satisfied by the donor countries. At the same time, the first necessary condition, i.e., the efforts of recipients to reduce poverty, should be met, too. Both of these conditions are required, since foreign aid will be less effective when recipient countries employ policies which are inconsistent with efforts to reduce poverty. To evaluate the first necessary condition, further decomposition of the head count ratio into different domestic groups and/or regions will give useful information. If we can obtain detailed data on domestic distribution and allocation of income transfer and subsidies, the first necessary condition can also be tested. 


\section{References}

Baulch, B., 1996, 'Neglected trade-offs in poverty measurement', IDS Bulletin, this volume

Behrman, J. R. and Sah, R. K., 1984, 'What role does equity play in the international distribution of development aid?' in M. Syrquin, L. Taylor, and L. E. Westpal (eds) Economic Structure and Performance, Academic Press

Besley, T. and R. Kanbur, 1988, 'Food subsidies and poverty alleviation', Economic Journal Vol 98: 701719

Cassen, R. and Associates, 1986, Does Aid Work?: Report to Intergovernmental Task Force, Oxford: Clarendon Press

Central Bureau of Statistics, 1985, 1992, Statistical Abstract of Israel, Tel Aviv

Chen, S., Datt, G. and Ravallion, M., 1993, 'Is poverty increasing in the developing world?', mimeo, Washington: World Bank

Chenery, H. B., Ahluwalia, M. S., Bell, C. L. G., Duloy, J. H. and Jolly, R., 1974, Redistribution with Growth, joint study by World Bank's Development Research Center and Institute of Development Studies at the University of Sussex, Oxford: Oxford University Press

Foster, J., Greer, J. and Thorbecke, E., 1984, 'A class of decomposable poverty measures', Econometrica Vol 52: $761-766$

Karima Korayem, 1994, 'The impact of structural adjustment and stabilization policies on the poor in Egypt, and how do they adapt', a paper prepared for TWF and UNICEF

Maxwell, S., 1996, 'Apples, pears and poverty reduction: an assessment of British bilateral aid', IDS Bulletin, this volume

Meier, G. M., 1995, Leading Issues in Economic Development, sixth edition, New York: Oxford University Press
Ministry of Foreign Affairs, 1994, Japan's ODA: Annual Report 1994, Economic Cooperation Bureau, Ministry of Foreign Affairs, the Government of Japan

OECD, 1989,1993, Geographical Distribution of Financial Flows to Developing Countries, Pans: Organization for Economic Cooperation and Development

Orr, R. M., Jr., 1990, The Emergence of Japan's Foreign Aid Power, New York: Columbia University Press

Ravallion, M., 1994, 'Measuning social welfare with and without poverty lines,' American Economic Review Vol 84: 359-364

Rix, A., 1990, 'Japan's Aid Programme: a new global agenda', International Development Issues Nol2, Australian International Development Assistance Bureau

Sen, A., 1976, 'Poverty: an ordinal approach to measurement', Econometrica Vol 44: 219-231

Summers, R. and Heston, A., 1991, 'The Penn World Table (Mark 5): an expanded set of international comparisons, 1950-1988', Quarterly Journal of Economics 106: $327-368$

Yasutomo, D. T., 1986, The Manner of Giving: Strategic Aid and Japanese Foreign Policy, MA: Lexington Books

White, H., 1996, 'How much aid is used for poverty reduction?', IDS Bulletin, this volume

White, H. and McGillivray, M., 1995, 'How well is aid allocated? Descriptive measures of aid allocation: a survey of methodology and results', Development and Change Vol 26: 163-183

World Bank, 1990, Poverty, World Development Report, Washington D.C. 


\begin{tabular}{|c|c|c|c|c|c|c|}
\hline \multirow{2}{*}{$\begin{array}{l}\text { Table } 1 \\
\text { Year }\end{array}$} & \multicolumn{6}{|c|}{$\begin{array}{l}\text { Rank correlations between the head count ratio and ODA } \\
\text { commitments }\end{array}$} \\
\hline & $\begin{array}{l}\text { Number of } \\
\text { recipient } \\
\text { countries }\end{array}$ & Japan & UK & USA & $\begin{array}{l}\text { Total } \\
\text { DAC }\end{array}$ & Multilateral \\
\hline $\begin{array}{l}1985 \\
1990\end{array}$ & $\begin{array}{l}40 \\
39\end{array}$ & $\begin{array}{r}0.070 \\
-0.127\end{array}$ & $\begin{array}{l}0.213 \\
0.101\end{array}$ & $\begin{array}{l}0.003 \\
0.131\end{array}$ & $\begin{array}{r}-0.076 \\
-0.149\end{array}$ & $\begin{array}{l}0.250 \\
0.259\end{array}$ \\
\hline Data source & \multicolumn{6}{|c|}{$\begin{array}{l}\text { Central Bureau of Statistics (1990), Chen et al. (1993), Korayem (1994), and OECD (1989 } \\
\text { 1993). }\end{array}$} \\
\hline
\end{tabular}

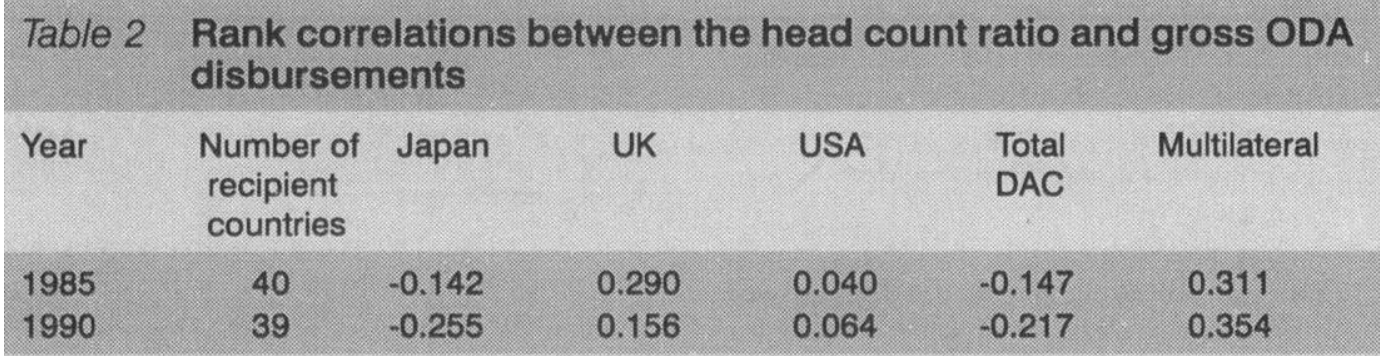

Data source Central Bureau of Statistics (1990), Chen et al. (1993), Korayem (1994), and OECD (1989, 1993).

\begin{tabular}{|c|c|c|c|c|c|c|}
\hline Year & $\begin{array}{l}\text { Number of } \\
\text { recipient } \\
\text { countries }\end{array}$ & Japan & UK & USA & $\begin{array}{l}\text { Total } \\
\text { DAC }\end{array}$ & Multilateral \\
\hline 1985 & 40 & -0.675 & -1.04 & -0.538 & -0.665 & -0.970 \\
\hline 1990 & 39 & -0.515 & -0.941 & -0.559 & -0.625 & -0.949 \\
\hline
\end{tabular}

Data source Central Bureau of Statistics (1990), Chenet al. (1993), Korayem (1994), and OECD (1989, 1993).

\section{Table 4 Average poverty alleviation effect of gross ODA disbursements

$\begin{array}{llllll}\text { Year } & \begin{array}{l}\text { Number of Japan UK USA } \\ \text { recipient } \\ \text { countries }\end{array} & \text { Total Multilateral } \\ \text { DAC } & & \end{array}$

$\begin{array}{lllllll}1985 & 40 & -0.548 & -1.361 & -0.476 & -0.671 & -1.072 \\ 1990 & 39 & -0.450 & -1.078 & -0.566 & -0.687 & -1.010\end{array}$ \\ Data source Central Bureau of Statistics (1985, 1992), Chen et al. (1993), Korayem (1994), and OECD $(1989,1993)$.}

